\title{
Eosinophilic gastroenteritis: a clinicopathological study of patients with disease of the mucosa, muscle layer, and subserosal tissues
}

\author{
N J Talley, R G Shorter, S F Phillips, A R Zinsmeister
}

\begin{abstract}
The aim of this study was to evaluate the clinicopathological spectrum of eosinophilic gastroenteritis and identify possible difficulties in establishing the diagnosis. All patients with a diagnosis of eosinophilic gastroenteritis, defined by the presence of gastrointestinal symptoms and eosinophilic infiltration of the gut (38), or a radiological diagnosis with peripheral eosinophilia (two), were identified from the Mayo Clinic records; in none was there evidence of extraintestinal disease. Patients were divided into three groups according to the Klein classification: predominant mucosal (23), muscular (12), or subserosal disease (five). A fourth group of patients (10) for comparison had abdominal symptoms and unexplained peripheral eosinophilia but no proven eosinophilic infiltration of the gut. It was found that a history of allergy was reported by 20 of $\mathbf{4 0}$ patients with eosinophilic gastroenteritis. Peripheral eosinophilia was absent in nine of 40 . The patients with subserosal disease were distinct from the other groups in presentation (abdominal bloating, ascites), higher eosinophil counts and in their dramatic responses to steroid therapy. Otherwise the patients were similar regarding demographic factors, presenting symptoms (abdominal pain, nausea, weight loss, diarrhoea), and laboratory parameters. The ESR was moderately raised in 10 of $\mathbf{4 0}$ patients. The disease may affect any area of the gastrointestinal tract; eosinophilic infiltration was documented in the oesophagus in one patient and in the colon in two cases. Endoscopic biopsies missed the diagnosis in five of 40 presumably because of patchy disease. Eosinophilic gastroenteritis should be considered in the differential diagnosis of unexplained gastrointestinal symptoms even in the absence of peripheral eosinophilia.
\end{abstract}

\section{Division of}

Gastroenterology,

Department of Pathology and Digestive Diseases Core Center, Mayo Clinic, Rochester, MN, USA

USA Talley

$R$ G Shorter

S F Phillips

A R Zinsmeister

Address for correspondence: Dr N J Talley,

Gastroenterology Unit, Mayo Clinic, Rochester, MN 55905 USA.

Accepted for publication 6 June 1989.
Infiltration of the gastrointestinal tract with eosinophils in association with recognisable clinical disease is rare. Since first described in 1937 by Kaijser, ' less than 150 cases have been reported, and these have consisted of single case reports or rather small case series. ${ }^{23}$ The pathogenesis of this condition is not understood but, after a review by Klein $e t$ al in 1970, the concept that eosinophilic infiltration can predominate in different layers of the gut wall has become widely accepted. ${ }^{+}$No studies have evaluated the clinical differences, however, between patients with predominant disease of the mucosal, muscle layer or subserosal tissues.
We aimed to evaluate the clinical spectrum of eosinophilic gastroenteritis in patients who had been diagnosed at the Mayo Clinic. We reviewed the clinical and laboratory features, assessed the value of clinicopathological correlations and evaluated possible difficulties in establishing the diagnosis.

\section{Methods}

\section{CASE DEFINITIONS}

Eosinophilic gastroenteritis was defined by three criteria: (1) the presence of gastrointestinal symptoms, (2) biopsies showing eosinophilic infiltration of one or more areas of the gastrointestinal tract from oesophagus to colon, or characteristic radiological findings with peripheral eosinophilia, and (3) no evidence of parasitic or extraintestinal disease..$^{2-5}$ As peripheral blood eosinophilia is not a universal finding in eosinophilic gastroenteritis occurring in $20-90 \%$ of cases, this was not included as a diagnostic criterion. ${ }^{25}$ All the cases were diagnosed by experienced gastroenterologists as having eosinophilic gastroenteritis.

A second group of patients was identified who had gastrointestinal symptoms, unexplained peripheral eosinophilia, but no proven eosinophilic infiltration of the gut and no evidence of parasitic infection or disease elsewhere. This second group was diagnosed as having 'unexplained eosinophilia'.

\section{PATIENT SELECTION}

Charts from Mayo Clinic patients, from 1950 to 1987 , with a diagnosis of eosinophilia, eosinophilic gastroenteritis, allergic gastroenteropathy, or the hypereosinophilic syndrome, were reviewed. The study was approved by the Institutional Review Board of Mayo Clinic. The medical histories were retrievable because since extensive indices based on clinical and histological diagnoses and surgical procedures. Each provider of care uses a unit (or dossier) medical record system whereby all data collected on an individual are assembled in one place. The system contains the medical histories of more than 4 million individuals and only about 300 have been lost in 80 years. The medical data contained in these records, comprising clinical, pathological, and therapeutic details, are collected by physicians engaged in subspecialty level medical care and are of high quality. Two patients with a diagnosis of eosinophilic gastroenteritis made in 1987-1988 were also prospectively enrolled in the present study. 
Exclusions included patients with parasitic infection (two), Menetrier's disease (one), Crohn's disease (one), coeliac disease (one), connective tissue disease (one), intestinal lymphomas (seven), other tumours (seven), primary amyloid (one), eosinophilic granuloma (one), and the Churg-Strauss syndrome (four). In addition, patients with the idiopathic hypereosinophilic syndrome were not included.

Using these methods, 40 patients with eosinophilic gastrointestinal disease, were identified; three cases had been described in earlier reports. ${ }^{6-8}$ Thirty eight patients had biopsy tissue showing eosinophilic infiltration of the gastrointestinal tract. The two remaining patients had been labelled as having eosinophilic gastroenteritis based on radiological changes in the small bowel characterised by very prominent folds, the clinical history, and peripheral eosinophilia. ${ }^{29}$ Biopsies were not diagnostic in these two cases.

A second group of 10 patients with unexplained gastrointestinal symptoms and peripheral eosinophilia were identified and included for comparison purposes. Of these patients, nine had negative radiological and/or biopsy studies; in one case eosinophilia had been transient and no studies had been undertaken.

Data were collected on demographic characteristics, presenting symptoms, number of years of symptoms before diagnosis and number of years of follow up, past history or family history of allergy (defined as a history of atopy, asthma, nasal polyps, hayfever, or drug allergy), a history of specific food intolerance or food allergy, serum IgE concentrations, the absolute eosinophil count and ESR, and evidence of steatorrhoea and protein losing enteropathy where available. All clinical and laboratory data were transcribed from the medical record onto a computer coding sheet for analysis. Biopsy specimens from 28 of the 40 patients with eosinophilic gastroenteritis were available. Where possible slides were reviewed by a single experienced histopathologist (RGS) blinded to the results of previous investigations. Abnormal eosinophilic infiltration was defined as at least 20 eosinophils per high power field either diffusely or multifocally; no attempt at exact quantification was undertaken in this study. In the remaining cases biopsy material collected elsewhere had usually been reviewed by a pathologist during the patient's evaluation at Mayo Clinic.

Patients were divided into those with (1) predominantly mucosal disease, defined as infiltration of the mucosa by eosinophils and/or evidence of mucosal edema on barium studies, no histological evidence of infiltration of muscle (where available), and no evidence of gastrointestinal obstruction or eosinophilic ascites; (2) predominant disease of the muscle layer, defined as documented complete or incomplete bowel obstruction and/or eosinophilic infiltration of the tunica muscularis with no evidence of eosinophilic ascites; (3) predominant subserosal disease, defined by the presence of eosinophilic infiltration of the gut and eosinophilic ascites; and (4) unexplained eosinophilia. ${ }^{+}$Patients with mucosal involvement who also had muscle layer disease were included in the latter group, and
TABLE I Age and sex distribution of patients with and without eosinophilic gastroenteritis

\begin{tabular}{|c|c|c|c|}
\hline \multirow[b]{2}{*}{$\begin{array}{l}\text { Patients with eosinophilic } \\
\text { gastrointestinal diseae }(n=40)\end{array}$} & \multicolumn{3}{|c|}{ Klein classification } \\
\hline & $\begin{array}{l}\text { Group } \\
(n)\end{array}$ & $\begin{array}{l}\text { Mean age } e^{\star} \text { at } \\
\text { diagnosis } \\
(S E M)\end{array}$ & $\begin{array}{l}\text { Sex ratiot } \\
\text { (male: } \\
\text { female })\end{array}$ \\
\hline \multicolumn{4}{|l|}{ Group 1} \\
\hline $\begin{array}{l}\text { a } \\
\text { Mucosal layer disease } \\
\text { b }\end{array}$ & 23 & $36 \cdot 7(4 \cdot 1)$ & $1 \cdot 4: 1$ \\
\hline Muscle layer disease & 12 & $35 \cdot 3(3 \cdot 0)$ & $1 \cdot 3: 1$ \\
\hline $\begin{array}{l}\text { c } \\
\text { Subserosal disease }\end{array}$ & 5 & $42 \cdot 0(8 \cdot 3)$ & $1 \cdot 4: 1$ \\
\hline $\begin{array}{l}\text { Group } 2 \\
\text { Patients without eosinophilic } \\
\text { gastrointestinal disease }\end{array}$ & 10 & $36 \cdot 1(5 \cdot 4)$ & $1 \cdot 5: 1$ \\
\hline
\end{tabular}

*ANOVA: $F=0 \cdot 18, p=0.91 ; \nmid \chi^{2}=0 \cdot 66, p=0 \cdot 88$.

patients with transmucosal disease and ascites were included in the subserosal group. In only two patients did further review of the biopsy material lead to a change in classification.

\section{Statistical analysis}

The association of symptoms and other variables with group membership was assessed using logistic regression methods based on an ordinal model (the Klein classification) adjusting for age, sex, and duration of symptoms before diagnosis. The alpha level of significance was set for individual variables at 0.05 ; all $\mathrm{p}$ values calculated were 2 tailed.

\section{Results}

The patients in the four groups were of similar age and sex (Table I). Of the 40 patients with proven eosinophilic gastroenteritis, $63 \%$ had histological and/or radiological evidence of antral disease (Figs 1, 2), 28\% had other areas of the stomach involved and $75 \%$ had involvement of the proximal small bowel (Fig 3). These numbers add up to more than $100 \%$, as many patients had multiple areas of disease. Of six patients where ileal tissue was obtained at surgery, $80 \%$ had disease (Fig 4). Five patients had colonic biopsies taken and $40 \%$ had colonic involvement, while only one patient had oesophageal biopsies obtained and eosinophilic infiltration was identified. The sites where tissue biopsies were obtained in the patients are summarised in Table II.

In three cases (two with mucosal disease and one with disease of the muscle layer), mucosal biopsies failed to confirm the diagnosis, which was later made by a full thickness surgical biopsy. In addition, two cases with very prominent folds in the small bowel, as well as a nodular filling defect in the duodenal bulb in one case and prominent gastric folds in the other, had normal mucosal biopsies. The presenting symptoms of the patients in each group are given in Table III. It can be seen that patients all complained of similar symptoms, except for abdominal bloating that was more common in patients with subserosal disease. Three patients complained of dysphagia, and in one case where oesophageal biopsies were obtained, eosinophilic infiltration was found. Two other patients presented with 


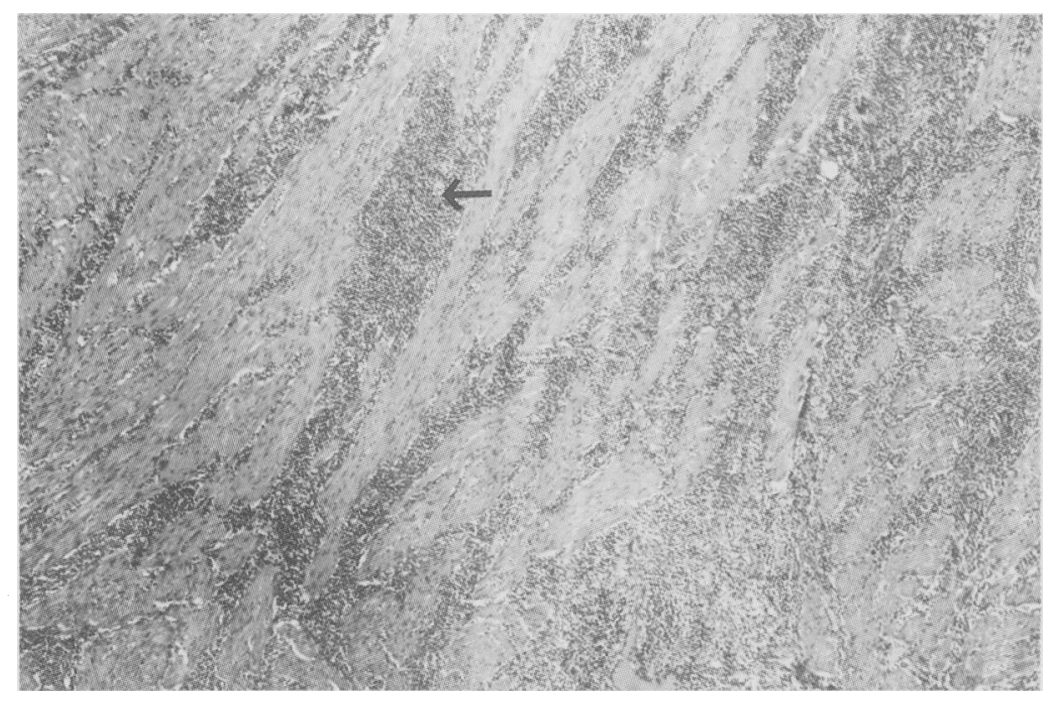

Figure 1: Stomach: pyloric muscle showing dense infiltration by eosinophils (arrow).

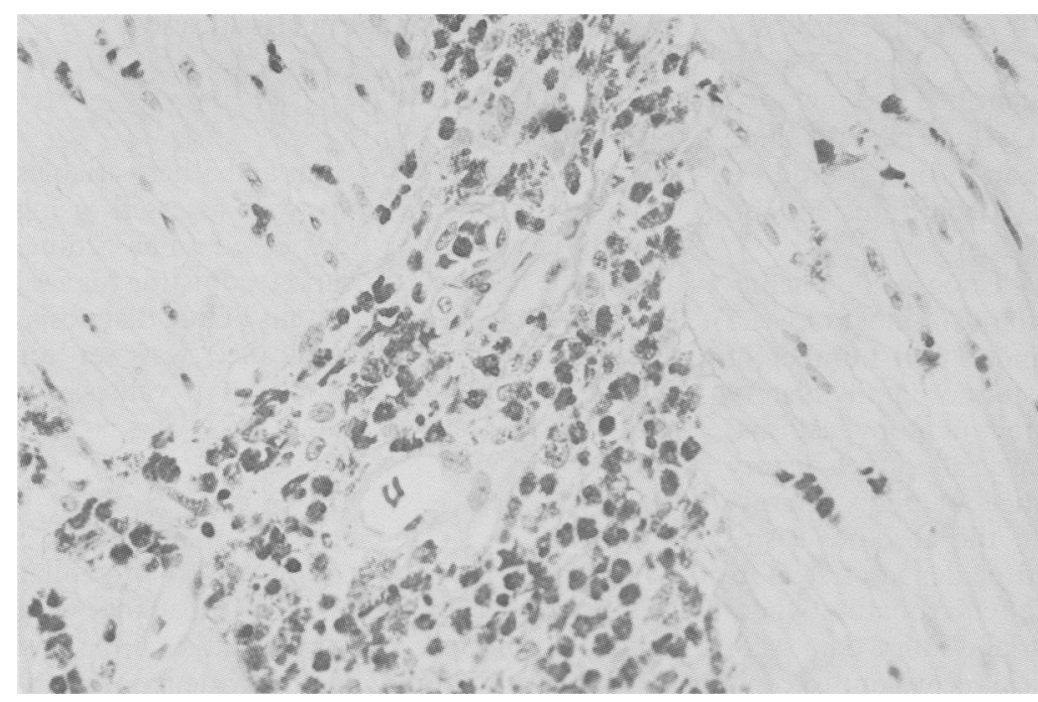

Figure 2: Stomach: muscularis propria showing eosinophil infiltration.

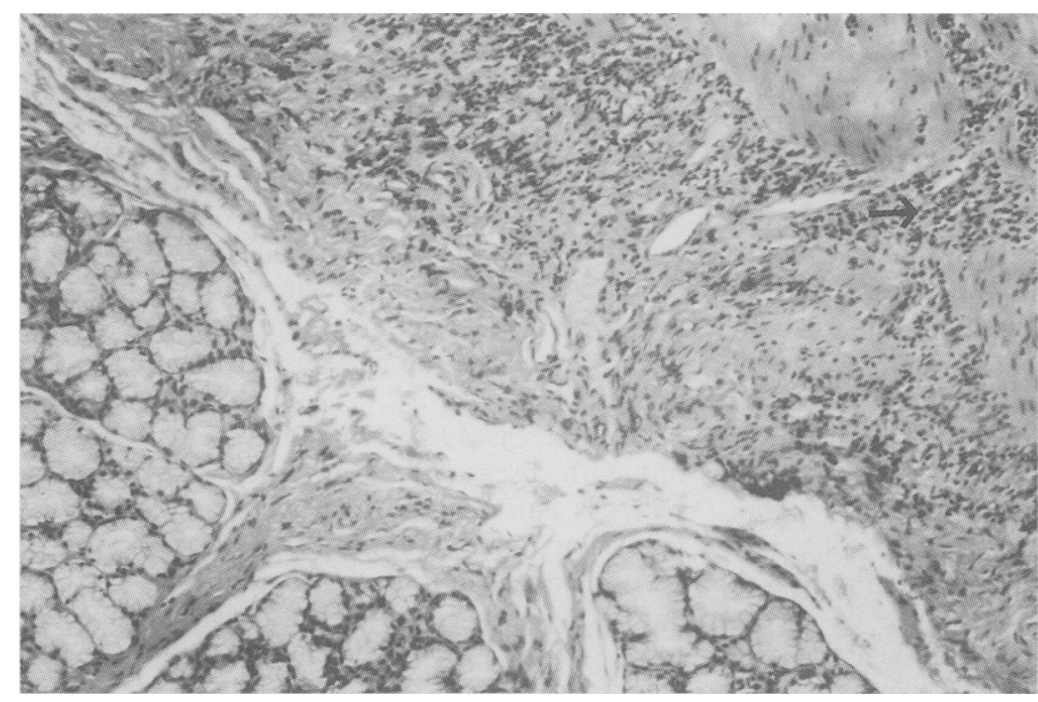

Figure 3: Duodenum (submucosa and Brunner's glands): Eosinophilic infiltration (arrow).

short stature at ages 12 and 13 years; both had evidence of a protein losing enteropathy, and one had steatorrhea.

In Table IV, the clinical and laboratory findings in all patients are summarised. Of the variables measured, only the circulating eosinophil count was significantly higher in patients with subserosal disease. The eosinophil count was normal in five of 23 patients with mucosal disease, three of 12 with muscle layer disease and one of five with subserosal disease. The ESR was 10 or higher in eight of 23 patients with mucosal layer disease, in two of 12 with muscle layer disease and nil in five with subserosal disease. Food intolerance or allergy was reported by $52 \%$ of patients with mucosal layer disease compared with none of the patients with muscle layer or subserosal involvement.

A response to therapy was defined as a remission of symptoms within one month, as follow up biopsies were not always available. The mean duration of follow up was $4 \cdot 8$ years. In nine of 12 patients with mucosal disease a response to prednisone was documented, compared with four of six with muscle layer disease. An additional four patients with mucosal disease were also treated with steroids, but no follow up was available regarding response rates. All patients with eosinophilic ascites had a dramatic remission when treated with corticosteroids. Only three patients with mucosal disease were prescribed chromolyn sodium, and one responded. Four patients with disease of the muscle layer presented with severe pyloric outlet obstruction which required surgery.

\section{Discussion}

A present study reports the largest clinical experience with eosinophilic gastroenteritis Importantly, this term is a restrictive misnomer; like others we found that the entire gastrointestinal tract may be involved, from oesophagus to colon. ${ }^{10-15}$ The apparent location of the disease in this series is likely to be disproportionately proximal as gastroscopic evaluation is the most common means of making the diagnosis.

Eosinophilic gastrointestinal disease is indeed rare; even at major referral centres, perhaps only one case per hundred thousand patients might be identified. Yet, the disease may be underdiagnosed. For example, in our study group, mucosal biopsies failed to show eosinophilic infiltrations in four cases with mucosal disease (presumably because the disease can be patchy) and in one case with muscle layer disease (as they may show no associated mucosal involvement); no patients with subserosal disease and ascites were misclassified..$^{2-4}$ Importantly, the peripheral eosinophil count was normal in $23 \%$ of patients with eosinophilic gastroenteritis, suggesting that this is not a reliable diagnostic criterion. Whether any of the 10 patients with unexplained eosinophilia in this study has eosinophilic infiltration of the gastrointestinal tract is unknown; they may represent further cases of eosinophilic gastroenteritis who were missed because of its patchy nature, or a form fruste of the disease. Our data suggest that mucosal and muscular layer eosinophilic gastroenteritis should be considered in the differential diagnosis of unexplained gastrointestinal symptoms even in the absence of peripheral eosinophilia.

The Klein classification, where patients are arbitrarily divided into those with predominantly mucosal, muscle layer or subserosal disease, is widely used, but no previous studies 


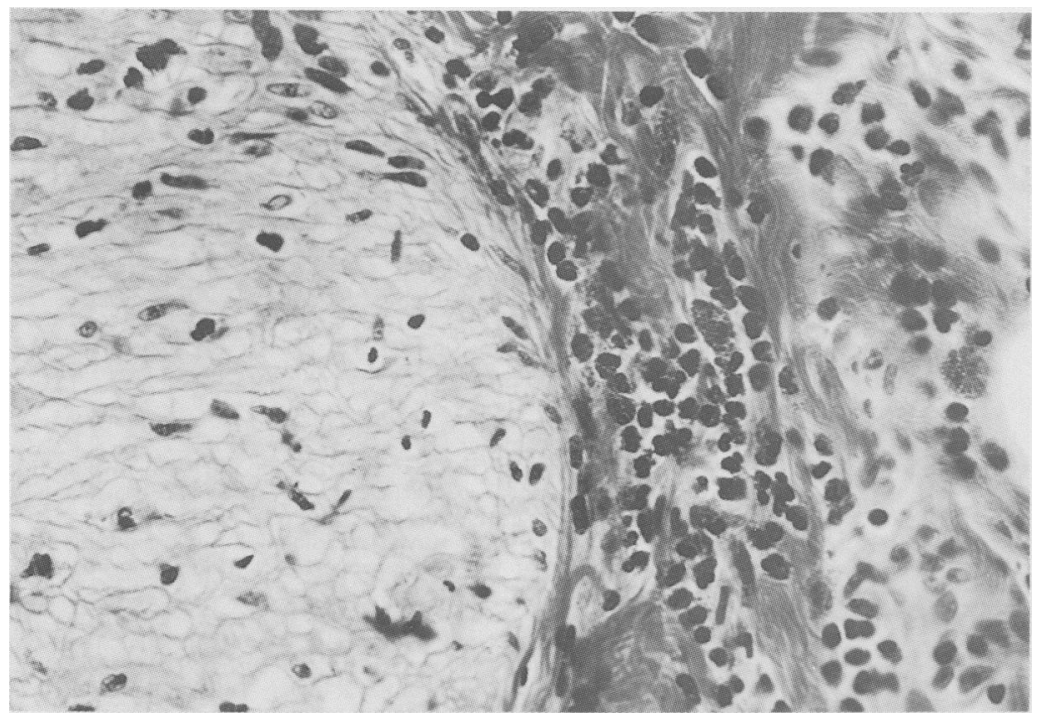

Figure 4: Ileum: muscularis propria and submucosa showing eosinophil infiltration.

TABLE II Distribution of biopsy specimens obtained from patients diagnosed as having eosinophilic gastroenteritis $(n=40)$

\begin{tabular}{lll}
\hline Site of biopsies & $\begin{array}{l}\text { Patients } \\
\text { biopsied at } \\
\text { each sitet }(n)\end{array}$ & $\begin{array}{l}\text { Patients with } \\
\text { eosinophilic } \\
\text { infiltration }(n)\end{array}$ \\
\hline Gastric antrum and body & 26 & 21 \\
Duodenum and proximal jejunum & 32 & 26 \\
Ileum (at surgery) & 6 & 5 \\
Rectum and colon & 5 & 2 \\
Oesophagus & 1 & 1 \\
Gall bladder and appendix & 1 & 1 \\
\hline
\end{tabular}

^Eight patients $(20 \%)$ had full thickness biopsies taken at laparotomy for diagnosis (three ileum, five stomach and/or small bowel) and one had surgery for pyloric outlet obstruction; three additional patients had surgery for pyloric outlet obstruction but were diagnosed preoperatively; +28 patients $(70 \%)$ had biopsies taken from multiple sites; $¥ T$ wo additional patients complained dysphagia but did not undergo esophageal biopsy; one of these patients had a diffusely narrowed esophagus on barium swallow examination. have analysed their patients to determine if clinical and laboratory parameters differ between such groups. We found that only one difference emerged between the groups; a very high eosinophil count was more likely to be associated with subserosal involvement. Subserosal disease also presented with ascites and had the best response to steroids, suggesting that this group is quite distinct from the mucosal and muscle layer groups. In contrast with other reports ${ }^{13}$ we found that the ESR was not invariably normal, as it was modestly raised in $25 \%$ of cases. It is noteworthy, that a past history of allergy was only reported by $50 \%$ of the eosinophilic gastroenteritis patients in this study and this suggests that a history of allergy may be of little help in making a diagnosis. ${ }^{13}{ }^{16-18}$

The pathogenesis of eosinophilic gastroenteritis is not understood; perhaps an excessive accumulation of eosinophils causes destruction of intestinal epithelium caused by the release of eosinophilic major basic protein, as has been found in the respiratory epithelium in asthma. ${ }^{19}$ In one report, two siblings with mucosal layer disease had activated degranulating eosinophils which correlated with the degree of histologic damage $^{20}$ but no other studies have been performed. Moreover, clear etiologic factors have not been defined.

Steroids remain the mainstay of therapy for eosinophilic gastroenteritis with good symptomatic responses being reported,, 313172122 and similar results were found in our groups. Trial elimination diets have occasionally been successful, but relapse is common. ${ }^{+17}$ The value of oral sodium chromoglycate is controversial ${ }^{2023}$ and was not impressive in this series. Unfortunately, no double blinded controlled trials have evaluated the benefit of any of these therapies, so the current recommendations are based only on anecdotal evidence.

TABLE III Presenting symptoms of eosinophilic gastrointestinal disease by disease group

\begin{tabular}{|c|c|c|c|c|c|c|}
\hline Symptom * & $\begin{array}{l}\text { Mucosal layer } \\
\text { disease } \\
\%(n=23)\end{array}$ & $\begin{array}{l}\text { Muscle layer disease } \\
\%(n=12)\end{array}$ & $\begin{array}{l}\text { Subserosal disease } \\
\text { and ascites } \\
\%(n=5)\end{array}$ & $\begin{array}{l}\text { No GI eosinophilic } \\
\text { disease identified } \\
\%(n=10)\end{array}$ & $\begin{array}{l}\text { Logisti } \\
\text { results } \\
\chi^{2} \dagger\end{array}$ & $p$ \\
\hline $\begin{array}{l}\text { Abdominal pain } \\
\text { Nausea/vomiting } \\
\text { Weight loss ( } \geq 5 \text { lbs) } \\
\text { Bloating } \\
\text { Diarrhoea }\end{array}$ & $\begin{array}{l}61 \\
57 \\
35 \\
13 \\
57\end{array}$ & $\begin{array}{l}75 \\
58 \\
25 \\
25 \\
33\end{array}$ & $\begin{array}{r}80 \\
40 \\
0 \\
60 \\
60\end{array}$ & $\begin{array}{l}90 \\
20 \\
30 \\
10 \\
40\end{array}$ & $\begin{array}{r}<1.0 \\
1.3 \\
1.5 \\
4.2 \\
<1.0\end{array}$ & $\begin{array}{c}\text { NS } \\
\text { NS } \\
\text { NS } \\
<0.05 \\
\text { NS }\end{array}$ \\
\hline
\end{tabular}

^An additional two patients with mucosal disease and one patient with muscle layer disease complained of dysphagia, and two other patients with mucosal layer disease presented with short stature; $t \chi^{2}$ value on $1 \mathrm{df}$ for entry into logistic regression model containing age sex and duration of symptoms before diagnosis.

TABLE IV Eosinophilic gastrointestinal disease: a comparison of disease groups

\begin{tabular}{|c|c|c|c|c|c|c|}
\hline \multirow[b]{2}{*}{ Variables } & \multirow[b]{2}{*}{$\begin{array}{l}\text { Mucosal layer } \\
\text { disease } \\
(n=23)\end{array}$} & \multirow[b]{2}{*}{$\begin{array}{l}\text { Muscle layer } \\
\text { disease } \\
(n=12)\end{array}$} & \multirow[b]{2}{*}{$\begin{array}{l}\text { Subserosal disease } \\
(n=5)\end{array}$} & \multirow{2}{*}{$\begin{array}{l}\text { NoGI } \\
\text { eosinophilic } \\
\text { disease } \\
\text { identified } \\
(n=10)\end{array}$} & \multicolumn{2}{|c|}{$\begin{array}{l}\text { Results of logistic } \\
\text { regression test }\end{array}$} \\
\hline & & & & & $\begin{array}{l}\text { Result } \\
\chi^{2 \star}\end{array}$ & Probability \\
\hline $\begin{array}{l}\text { No years of symptoms before diagnosis }(\mathbf{n}) \dagger \\
(\text { mean SEM }))\end{array}$ & $5 \cdot 1(0 \cdot 9)$ & $3 \cdot 0(1 \cdot 1)$ & $5 \cdot 4(2 \cdot 9)$ & $9 \cdot 2(3 \cdot 8)$ & - & - \\
\hline Past history of allergy & $52 \%$ & $33 \%$ & $80 \%$ & $56 \%$ & $<1 \cdot 0$ & NS \\
\hline Family history of allergy & $44 \%$ & $33 \%$ & $0 \%$ & $44 \%$ & $1 \cdot 2$ & NS \\
\hline Food intolerance or allergy reported & $52 \%$ & $0 \%$ & $0 \%$ & $10 \%$ & $1 \cdot 6$ & NS \\
\hline $\mathrm{ESR}(\operatorname{mean}(\mathrm{SEM}))$ & $12(3)$ & $6(2)$ & $3(1)$ & $7(2)$ & $<1 \cdot 0$ & NS \\
\hline $\begin{array}{l}\text { Blood eosinophil count (median } \\
\text { (interquartile range)) }\end{array}$ & $2241(739-4235)$ & $1303(365-2234)$ & $8413(1037-14521)$ & $1882(979-2973)$ & $6 \cdot 0$ & $<0.05$ \\
\hline Malabsorption (steatorrhea) & $30 \%$ & $25 \%$ & $20 \%$ & $10 \%$ & $<1 \cdot 0$ & NS \\
\hline Protein losing enteropathy & $30 \%$ & $17 \%$ & $0 \%$ & $0 \%$ & $1 \cdot 2$ & NS \\
\hline
\end{tabular}

${ }^{\star} \chi^{2}$ value (on $1 \mathrm{df}$ ) for entry into the model containing age, sex, duration of symptoms before diagnosis; + Forced into the model; $\ddagger U$ pper limit of normal: 760 eosinophils $/ \mu$ l. 
In conclusion, we have reviewed 40 patients with eosinophilic gastrointestinal disease and 10 patients with gastrointestinal symptoms and peripheral eosinophilia but no evidence of eosinophilic infiltration of the gut. We have confirmed that eosinophilic gastrointestinal disease may involve the entire gastrointestinal tract; in those patients with documented eosinophilic infiltration of the stomach or small intestine, a systematic search for possible colonic or esophageal involvement would be of interest. Our data suggest that mucosal and muscle layer (but not subserosal) disease may cause symptoms that could be confused with functional bowel disease; eosinophilic gastrointestinal disease should be suspected in the presence of unexplained chronic or relapsing gastrointestinal symptoms. Peripheral eosinophilia may be absent, the ESR can be moderately raised, the disease may be patchy, endoscopic biopsies can miss the diagnosis, and about half the patients will not report a history of allergy. The pathogenesis of this rare disease remains obscure, but the diagnosis should not be missed as anecdotally steroid therapy may often be effective.

Presented in part as an abstract at the Gastroenterological Society of Australia in Alice Springs, October 1987. Supported in part by grant DK34988 from the National Institutes of Health, Bethesda, MD.

1 Kaijser R. Zur Kenntnis der allegischen Affektioner desima Verdauungskanal von Standpunkt desima Chirurgen aus. Arch Klin Chir 1937; 188: 36-64.

2 Blackshaw AJ, Levison DA. Eosinophilic infiltrates of the gastrointestinal tract. 7 Clin Pathol 1986; 39: 1-7.

3 Cello JP. Eosinophilic gastroenteritis - a complex disease entity. Am F Med 1979; 67: 1097-104.

4 Klein NC, Hargrove RL, Sleisenger MH, Jeffries GH. Eosinophilic gastroenteritis. Medicine 1970; 49: 299-319.

5 Spry CJF. Eosinophilic gastroenteritis. In: Bouchier IAD, Allan RN, Hodgson HJF, et al, eds. Textbook of gastroenterology. London: Ballière Tindall, 1984: 596-8.

6 Scudamore HH, Phillips SF, Swedlund HA, Gleich GJ.
Food allergy manifested by eosinophilia, elevated immunoglobulin $\mathrm{E}$ level, and protein losing enteropathy: the syndrome of allergic gastroenteropathy. $\mathcal{F}$ Allergy Clin Immunol 1982; 70: 129-38.

7 McNabb PC, Fleming RC, Higgins JA, Davis GL. Transmural eosinophilic gastroenteritis with ascites. Mayo Clin Proc 1979; 54: 119-22.

8 Zora JA, O'Connell EJ, Sachs MI, Hoffman AD. Eosinophilic gastroenteritis: A case report and review of the literature. Ann Allergy 1984; 53: 45-7.

9 Goldberg HI, O'Kieffe D, Jenis EH, Boyce HW. Diffuse eosinophilic gastroenteritis. Am $\mathcal{F}$ Roentgenol Radium The Nuc Med 1973; 119: 342-51

10 Haberkern CM, Christie DL, Haas JE. Eosinophilic gastroenteritis presenting as ileocolitis. Gastroenterology 1978; 74: 896-99.

11 Schulze K, Mitros FA. Eosinophilic gastroenteritis involving the ileocecal area. Dis Colon Rectum 1979; 22: 47-50.

12 Tedesco FJ, Huckaby CB, Hamby-Allen M, Ewing GC. Eosinophilic ileocolitis. Expanding spectrum of eosinophilic Eosinophilic ileocolitis. Expanding spectrum

13 Chisholm JC, Martin HI. Eosinophilic gastroenteritis with rectal involvement: case report and a review of the literature. rectal involvement: case report and

14 Moore D, Lichtman S, Lentz J, Stringer D, Sherman P. Eosinophilic gastroenteritis presenting in an adolescent with isolated colonic involvement. Gut 1986; 27: 1219-22.

15 Dobbins JW, Sheahan DG, Behar J. Eosinophilic gastroenteritis with esophageal involvement. Gastroenterology 1977; 72: 1312-6.

16 Ingelfinger FJ, Lowell FC, Franklin W. Gastrointestina allergy. $N$ Engl f Med 1949; 241: 303-8, 337-40.

17 Leinbach GE, Rubin CE. Eosinophilic gastroenteritis: a simple reaction to food allergens? Gastroenterology $1970 ; 59$ 874-89.

18 Caldwell JH, Mekhjian HS, Hurtubise PE, Beman FM. Eosinophilic gastroenteritis with obstruction. Immunological studies of seven patients. Gastroenterology 1978; 74: 825-8

19 Frigas E, Loegering DA, Solley GO, Farrow GM, Gleich GJ Elevated levels of the eosinophil major basic protein in the sputum of patients with bronchial asthma. Mayo Clin Pro 1981; 56: 345-53.

20 Keshavarzian A, Saverymuttu SH, Tai PC, et al. Activated eosinophils in familial eosinophilic gastroenteritis. Gastroenterology 1985; 88: 1041-9.

21 Caldwell JH, Tennenbaum JI, Bronstein HA. Serum IgE in eosinophilic gastroenteritis. Response to intestinal challenge in two cases. N Engl F Med 1975; 292: 1388-90.

22 Robert F, Omura E, Durant JR. Mucosal eosinophilic gastroenteritis with systemic involvement. Am 7 Med 1977; 62: $139-43$

23 Heatley RV, Harris A, Atkinson M. Treatment of a patient with clinical features of eosinophilic gastroenteritis and polyarteritis nodosa with oral sodium cromoglycate. Dig Dis Sci 1980; 25: 470-2.

24 Moots RJ, Prouse P, Gumpel JM. Near fatal eosinophilic gastroenteritis responding to oral sodium chromoglycate. Gut 1988; 29: 1282-5. 